\title{
RENDIMENTO E COMPOSIÇÃO CENTESIMAL DE FILÉS E GARNE MECANICAMENTE SEPARADA DE SARAMUNETES (Pseudupeneus maculatus BLOCH, 1793)
}

\section{Yield and centesimal composition of fillets and mechanically separate meat of spotted goatfish (Pseudupeneus maculatus Bloch, 1793)}

\author{
Pedro Luiz Silva de Sá Júnior ${ }^{1}$, Leandro José da Silva², Humber Agrelli de Andrade ${ }^{3}$, \\ Paulo Roberto Campagnoli de Oliveira Filho ${ }^{4}$ \\ ${ }^{1}$ Mestrando do Programa de Pós-Graduação em Ciência e Tecnologia de Alimentos, na \\ Universidade Federal Rural de Pernambuco, bolsista Capes. E-mail: gastroluizsa@gmail.com \\ ${ }^{2}$ Graduando em Engenharia de Pesca na Universidade Federal Rural de Pernambuco. \\ E-mail: leo leandro 89@hotmail.com \\ ${ }^{3}$ Docente, Laboratório de Modelagem Artística (MOE), Universidade Federal Rural de Pernambuco. \\ E-mail: humber.andrade@gmail.com \\ ${ }^{4}$ Docente, Laboratório de Tecnologia do Pescado (Latpesc), Universidade Federal Rural de Pernambuco. \\ E-mail: paulocoliveira79@hotmail.com
}

\section{RESUMO}

O objetivo do estudo foi avaliar o rendimento e a composição centesimal de filés de saramunetes (Pseudupeneus maculatus) e da carne mecanicamente separada (CMS) sem lavar, com uma e duas lavagens com água. Os saramunetes apresentaram rendimento de filés ligeiramente inferior quando comparados com outros peixes. Por outro lado, o rendimento da CMS foi próximo ao observado em outros peixes comerciais. A umidade das CMS foi maior $(\mathrm{P}<0,05)$ que a dos filés, sendo que o aumento do número de lavagens da CMS causou aumento da umidade. Os filés apresentaram alto teor proteico, superior $(\mathrm{P}<$ 0,05 ) ao da CMS, e baixa porcentagem de lipídeos. A CMS apresentou porcentagem de lipídeos superior à dos filés, e o aumento do número de lavagens da CMS causou diminuição $(\mathrm{P}<0,05)$ na porcentagem de lipídeos. A porcentagem de cinzas da CMS foi superior à dos filés e houve também diminuição $(\mathrm{P}<0,05)$ após a lavagem. A composição centesimal da CMS sem lavar foi próxima à do filé. Portanto, recomenda-se a não lavagem da CMS de saramunetes para evitar perdas de compostos nutricionais (proteína, lipídeos e cinzas) e a formação de resíduos líquidos.

Palavras-chave: pesca artesanal, peixe marinho, qualidade do pescado, subprodutos de pescado.

Recebido em: 06/12/2019

Aprovado em: 29/05/2020

Publicado em: 30/08/2020 


\section{ABSTRACT}

The objective of the study was to evaluate the yield and the centesimal composition of spotted goatfish fillets and mechanically separated meat (MSM) without washing, with one and two washes with water. The spotted goatfish presented slightly lower fillet yield when compared to other fish. On the other hand, the MSM yield is close to that observed in other commercial fish. The moisture of the MSM was higher $(P<0.05)$ than the spotted goatfish fillets, and the increase in the number of MSM washes caused an increase of moisture. The fillets had high protein content, higher $(P<0.05)$ than MSM. The fillets presented low percentage of lipids. The MSM showed a higher percentage of lipids than the fillets, and the increase in the number of MSM washes caused a decrease $(P<0.05)$ in the percentage of lipids. The percentage of ashes from MSM was higher than the fillets and there was also decrease $(P<0.05)$ after washing. The centesimal composition of the MSM was close to that of the fillet. However, washing MSM increases the moisture content and decreases protein, lipid and ash. Therefore, it is recommended not to wash the MSM to avoid losses of nutritional compounds (protein, lipids and ash) and the formation of liquid residues.

Keywords: artisanal fishing, marine fish, quality of fish, fish by-products.

\section{INTRODUÇÃO}

A pesca artesanal é a via majoritária de produção de pescado capturado em todo o mundo, empregando mais de 90\% dos 35 milhões de pescadores (FAO, 2018). Das 803 mil toneladas de pescado capturado no Brasil no ano de 2011, apenas $20 \%$ foram produzidos nas regiões Sul e Sudeste, locais onde a pesca industrial é realizada com maior intensidade. A partir dessa constatação, infere-se que a pesca artesanal ainda é a principal via de produção de pescado capturado no Brasil. O Nordeste brasileiro, região que possui a maior população pesqueira do país, foi o principal produtor de pescado do Brasil em 2011, sendo a pesca artesanal marinha a principal via extrativa (Brasil, 2012). A exploração artesanal dos recursos pesqueiros do Nordeste está concentrada principalmente nas capturas de espécies pelágicas (agulhinhas e sardinhas), demersais e bentônicas (saramunete, cioba, moluscos e crustáceos como lagostas e camarões) (Castello, 2010).

No Brasil, apesar da preferência por carnes bovina e avícola (Lopes; Oliveira \& Ramos, 2016), o consumo per capita de pescado tem apresentado um crescimento significativo, evoluindo de 7,62 kg em 1996 para $11 \mathrm{~kg}$ no ano de 2011. Contudo, esse índice ainda se encontra abaixo do preconizado pela Organização Mundial de Saúde, que é de $12 \mathrm{~kg}$ de pescado ao ano (Brasil, 2012). Além das características geográficas e culturais, outros fatores exercem influência no perfil do consumo de pescado pela população brasileira. Lopes, Oliveira e Ramos (2016), em estudo relacionado ao consumo nacional de carne de pescado, verificaram que os altos preços de compra e a falta de praticidade no preparo de refeições à base desse tipo de proteína animal são fatores que concorrem para a reduzida procura por produtos pesqueiros.

Sua imensa capacidade produtiva, aliada ao atual crescimento mundial do consumo, ressalta o grande potencial do Brasil no nicho de pescado e produtos derivados. Todavia, visando impulsionar o índice de consumo nacional de pescado, faz-se necessário o desen- 
volvimento de estudos que reduzam o preço ao consumidor final, assim como o desenvolvimento de tecnologias de produtos que ofereçam maior facilidade de preparo.

O saramunete (Pseudupeneus maculatus) é uma espécie de peixe da família dos mulídeos que habita águas com profundidades inferiores a $90 \mathrm{~m}$, em áreas com fundos rochosos e coralinos, bolsões de areia e cascalho ou bancos de algas próximos da costa de ilhas oceânicas (Cardoso et al., 2018). Possui corpo raso, alongado e fusiforme com cabeça de tamanho moderado. Suas nadadeiras dorsais são separadas, e um longo e flexível par de barbilhões encontra-se logo abaixo da mandíbula. Sua coloração varia de acordo com seu habitat, podendo ser de um colorido geral acinzentado claro ou avermelhado com manchas amareladas nas margens das escamas (Humann \& Deloach, 2014; Santana; Morize \& Lessa, 2006; Jatobá \& Oliveira Filho, 2017). No Brasil a exploração dessa espécie destaca-se no litoral norte do estado de Pernambuco, onde constitui um recurso pesqueiro de grande importância econômica para a pesca artesanal. No ano de 2011, a produção brasileira de saramunete chegou a 451 toneladas (Brasil, 2012), sendo comercializadas em âmbito nacional ou exportadas para países com expressiva demanda, como Estados Unidos e França (Silva et al., 2016).

Aproximadamente $88 \%$ dos 170 milhões de toneladas de pescado produzidos no ano de 2016 foram destinados ao consumo humano (FAO, 2018). Contudo, grande parte do pescado que chega ao consumidor final passou por algum nível de processamento. A expansão da rede de processamento de pescado tem ocasionado o crescimento da produção de resíduos, tais como cabeças, nadadeiras, vísceras, carcaças e carnes aderidas aos ossos (Arvanitoyannis \& Tserkezou, 2014).

O aproveitamento dos subprodutos do processamento do pescado tem se intensificado nas últimas décadas como forma de mitigar os negativos impactos ambientais ocasionados pelo descarte direto, propiciar ganhos econômicos e ampliar a produção de alimentos (Olsen; Toppe \& Karunasagar, 2014). Diversas estratégias vêm sendo utilizadas como forma de utilizar os resíduos do processamento pesqueiro. Uma das possibilidades é a produção de carne mecanicamente separa (CMS), material obtido a partir da separação da carne aderida a espinhaços de peixe (Borgogno et al., 2017). De acordo com a legislação brasileira, a CMS de pescado é o produto congelado obtido de pescado, envolvendo a retirada da cabeça, a evisceração, a limpeza destes e a separação mecânica da carne das demais estruturas inerentes à espécie, como espinhas, ossos e pele (Brasil, 2017).

Uma vasta gama de estudos relacionados à elaboração e otimização de produtos alimentícios derivados de pescado que contêm em sua composição CMS tem sido desenvolvida, tais como em salsichas (Lago et al., 2017) e fishburgers (Secci et al., 2017). Dessa forma, a utilização da CMS no desenvolvimento de novos produtos pesqueiros mostra-se como uma alternativa para reduzir a quantidade de resíduos descartados no meio ambiente, elevar o aproveitamento do material cárneo do pescado, atrair consumidores que buscam alimentos de fácil preparo e alto valor nutricional, além de ampliar os ganhos econômicos do setor.

A lavagem da CMS empregada em grandes plantas de processamento de pescado é realizada em sistema contínuo por meio da utilização de um tanque de lixiviação com tela rotativa. Esse equipamento possui pás que são ativadas automaticamente quando o tanque é preenchido até um nível predeterminado. A carne de pescado lavada é drenada através da tela rotativa antes do próximo ciclo. Esse passo é repetido de acordo com o número de ciclos de lavagem necessário (Okasaki \& Kimura, 2014). Os impactos do processo de la- 
vagem sobre a qualidade da CMS são de grande relevância. Por meio da lavagem ocorre a remoção de microrganismos deteriorantes, compostos odoríferos, proteínas sarcoplasmáticas, enzimas, gordura, sangue e pigmentos. Esses componentes podem catalisar processos de degradação proteica, oxidação lipídica, assim como alterações indesejadas na coloração do material cárneo. Dessa forma, a lavagem confere à CMS melhor qualidade organoléptica ao longo de sua conservação (Alcalde; Cavenaghi-Altemio \& Fonseca, 2017).

A espécie do pescado e seu frescor, o período de captura, as características do hábitat e o tipo de produto final desejado são fatores que determinam a quantidade de água e o número de ciclos empregados na lavagem de seu material cárneo (Priyadarshini et al., 2017). Além de poder acarretar a perda de proteínas miofibrilares quando aplicados em excesso, os ciclos de lavagem realizados nas indústrias de processamento de pescado geram grande volume de efluentes que podem causar danos severos ao meio ambiente (Priyadarshini et al., 2017). Portanto, estudos que avaliem os resultados da utilização do processo de lavagem da carne mecanicamente separada são de suma importância, tanto para a redução de efluentes nocivos ao meio ambiente quanto para o aprimoramento da qualidade de produtos pesqueiros.

O objetivo do presente estudo foi avaliar o rendimento e a composição centesimal de filés de saramunetes e da carne mecanicamente separada obtida do espinhaço sem lavar, com uma e duas lavagens.

\section{MATERIAL E MÉTODOS}

\section{Matéria-prima}

Para o experimento foram adquiridos $66 \mathrm{~kg}$ de saramunetes (Pseudupeneus maculatus) provenientes, com o máximo de frescor, de pescadores artesanais da Ilha de Itamaracá, município localizado no litoral norte do estado de Pernambuco em $7^{\circ} 45^{\prime} 0^{\prime \prime}$ Sul e $34^{\circ} 51^{\prime}$ $0^{\prime \prime}$ Oeste. Os peixes foram acondicionados em caixas térmicas com gelo em escamas e levados ao Laboratório de Tecnologia do Pescado, pertencente ao Departamento de Pesca e Aquicultura da Universidade Federal Rural de Pernambuco, Recife/PE. No laboratório, os peixes foram lavados com água clorada (5 ppm) para retirada do muco superficial e realizada a filetagem segundo o método descrito por Santos et al. (2016).

$\mathrm{Na}$ primeira etapa do processo de filetagem foram retirados escamas, vísceras, cabeça e filés com pele. Depois de separadas as peles dos filés, estes foram armazenados congelados em freezer comercial a $-20^{\circ} \mathrm{C}$, enquanto os espinhaços foram passados por uma desossadora mecânica $\left(\mathrm{PV}^{\circledR} 150\right)$ e a CMS obtida foi embalada em sacos de polietileno de baixa densidade contendo $500 \mathrm{~g}$ de massa cada um. Foram considerados três tratamentos quanto ao número de lavagens da CMS: zero (CMS não lavada), uma ou duas vezes. Para o tratamento "CMS não lavada", os sacos de polietileno de baixa densidade com a CMS foram diretamente mantidos congelados $\left(-20^{\circ} \mathrm{C}\right) \log$ o após o processamento. Para os tratamentos com processo de lavagem, foram utilizadas três partes de água gelada $\left(1^{\circ} \mathrm{C}\right)$ para uma parte de CMS. O material foi misturado por 2 minutos e deixado em repouso por 3 minutos. Posteriormente, o material foi filtrado em saco de nylon (porosidade de aproximadamente $0,042 \mathrm{~mm}^{2}$ ) e prensado manualmente até a retirada do excesso de água. No caso do tratamento com duas lavagens, o processo descrito acima foi repetido mais uma vez, de acordo com Oliveira Filho, Viegas, Kamimura e Trindade (2012). As 
matérias-primas de todos os tratamentos foram armazenadas em freezer $\left(-20^{\circ} \mathrm{C}\right)$ durante 5 dias antes da análise de composição centesimal.

\section{Composição centesimal}

A composição centesimal dos filés de saramunete e da carne mecanicamente separada obtida do espinhaço (CMS) sem lavar, com uma ou duas lavagens foi realizada em triplicatas de acordo com a metodologia oficial da AOAC (1999). A umidade foi calculada por gravimetria em estufa com circulação de ar forçada a $105{ }^{\circ} \mathrm{C}$ até se atingir peso constante, resultando na matéria seca utilizada nas demais análises. A proteína bruta foi calculada a partir do método de Kjeldahl $(\mathrm{N} x$ 6,25), a gordura foi extraída com éter de petróleo em um extrator tipo Soxhlet e as cinzas foram obtidas por meio de incineração em mufla a $550{ }^{\circ} \mathrm{C}$ por 5 horas.

\section{Análise estatística}

A análise estatística foi realizada primeiramente verificando os pré-requisitos de normalidade (teste de Shapiro-Wilk) e de homocedasticidade (teste de Bartlett). Após a verificação desses pré-requisitos, os resultados da composição centesimal foram submetidos à Análise de Variância (Anova) para verificar se havia evidências de diferenças significativas entre as médias nos diferentes tratamentos ao nível de 5\% de probabilidade. A seguir procedeu-se com o pós-teste de Tukey para verificar quais eram os tratamentos com evidências de diferenças entre si. As análises foram realizadas com o auxílio do programa $R(R$ Core Team, 2018).

\section{RESULTADOS E DISCUSSÃO}

\section{Rendimento}

Um resumo dos resultados gerais quanto aos pesos médios dos componentes e da análise de rendimento é mostrado na Tabela I.

\begin{tabular}{|c|c|c|}
\hline Variáveis & Peso (g) & Rendimento (\%) \\
\hline Peixe inteiro & 66.000 & ---- \\
\hline Filé & 18.177 & 27,5 \\
\hline Espinhaço sem nadadeiras & 10.155 & 15,4 \\
\hline $\mathrm{CMS}$ & 5.433 & $53,5^{1}$ \\
\hline CMS & & $8,2^{2}$ \\
\hline
\end{tabular}

\footnotetext{
${ }^{1}$ Rendimento em relação ao espinhaço.

${ }^{2}$ Rendimento em relação ao peixe inteiro.
}

O peso médio dos saramunetes $(160,8 \pm 30,4 \mathrm{~g} ; \bar{x} \pm s)$ observado neste trabalho foi superior ao do estudo de Santos et al. (2016), que encontraram peso médio de $126 \mathrm{~g}$. O oposto ocorreu quanto ao rendimento de filés que, no presente trabalho, foi de $27,5 \%$ e no observado por Santos et al. (2016) foi de 38\%, ao utilizar o mesmo método de filetagem. Isso pode ter acontecido pela falta de prática de filetagem dos pesquisadores, ou porque os saramunetes do presente estudo foram maiores. Se o crescimento das diferentes partes do 
corpo é proporcional (alometria), peixes de maior porte podem apresentar maior rendimento de outros componentes corporais, tais como a cabeça e as vísceras, por exemplo. $\mathrm{O}$ rendimento de filés verificado no presente trabalho se mostrou ligeiramente inferior quando comparado ao rendimento de filés de outras espécies de relevante valor comercial, como a tilápia do Nilo (Oreochromis niloticus, 30\% a 35\%) (Oliveira Filho; Viegas; Kamimura \& Trindade, 2012), a truta arco-íris (Oncorhynchus mykiss, 38,03\% a 41,17\%) (Souza et al., 2015) e a corvina-legítima (Argyrosomus regiu, 38,4\%) (Lazo; Guerrero \& Alexi, 2017).

Com relação ao rendimento de espinhaço, os valores do presente estudo foram praticamente a metade (15,4\%) do observado por Santos et al. (2016) (26,7\%). Essa diferença é em grande medida explicada pelo fato de que Santos et al. (2016) avaliaram o peso do espinhaço em conjunto com as nadadeiras, procedimento esse que não foi adotado neste trabalho.

O rendimento de carne mecanicamente separada (CMS) relativo ao peso do espinhaço de onde ela foi extraída $(53,5 \%)$ foi próximo do obtido com espinhaços de bagres africanos (49,8\%) (Durães et al., 2012) e de tilápias do Nilo (53\%) (Oliveira Filho et al., 2010). No entanto, se for calculado o rendimento da CMS em relação ao saramunete inteiro, o valor cai para 8,2\% (Tabela I). Apesar de não apresentar um alto rendimento da CMS em relação ao peixe inteiro, o espinhaço dos saramunetes é geralmente descartado pelas indústrias de processamento. Com o aproveitamento da CMS, a indústria pode ter mais opções de produtos a serem elaborados, como salsichas (Lago et al., 2017), nuggets e fishburgers (Secci et al., 2017), em vez de produzir somente filés, que é o mais realizado atualmente. Com essa possibilidade, a indústria pode fazer um melhor aproveitamento do pescado, diminuindo os custos de produção e estimulando o setor de fornecedores, que são os pescadores artesanais. Outra vantagem é para o consumidor, que poderá ter mais opções de produtos de pescado no mercado, além de preços mais acessíveis por ser utilizada na elaboração desses produtos a CMS obtida dos espinhaços. Outro fator que vale destacar também é a diminuição do descarte de resíduos de pescado ao meio ambiente.

No entanto, os aproveitamentos de filé e CMS podem apresentar variações de acordo com a espécie, o habitat, o hábito alimentar, a técnica de filetagem aplicada e o tipo de equipamento usado na separação mecânica da carne (Santos et al., 2016).

\section{Composição centesimal}

A composição centesimal dos filés de saramunete e da carne mecanicamente separada (CMS) obtida do espinhaço sem lavar, com uma e duas lavagens consta na Tabela II.

Tabela II - Composição centesimal (média \pm desvio padrão) dos filés de saramunete e da carne mecanicamente separada (CMS) obtida do espinhaço sem lavar (0), com uma lavagem (1) e com duas lavagens $(2)^{1,2}$

\begin{tabular}{ccccc}
\hline Composição & Filés de & \multicolumn{3}{c}{ Lavagem da carne mecanicamente separada (CMS) } \\
\cline { 3 - 5 } centesimal (\%) & saramunete & $\mathbf{0}$ & $\mathbf{1}$ & $\mathbf{2}$ \\
\hline Umidade & $78,23 \pm 0,10 \mathrm{~d}$ & $80,06 \pm 0,12 \mathrm{c}$ & $82,42 \pm 0,02 \mathrm{~b}$ & $88,38 \pm 0,12 \mathrm{a}$ \\
Proteína & $19,22 \pm 0,56 \mathrm{a}$ & $17,99 \pm 0,07 \mathrm{~b}$ & $15,27 \pm 0,05 \mathrm{c}$ & $9,99 \pm 0,33 \mathrm{~d}$ \\
Lipídeos & $0,25 \pm 0,09 \mathrm{c}$ & $1,34 \pm 0,11 \mathrm{a}$ & $0,95 \pm 0,06 \mathrm{~b}$ & $0,32 \pm 0,10 \mathrm{c}$ \\
Cinzas & $1,20 \pm 0,01 \mathrm{~b}$ & $1,28 \pm 0,01 \mathrm{a}$ & $0,71 \pm 0,01 \mathrm{c}$ & $0,37 \pm 0,02 \mathrm{~d}$ \\
\hline
\end{tabular}

${ }^{1}$ Valores expressos na matéria úmida.

${ }^{2}$ Letras diferentes na mesma linha indicam diferença significativa $(\mathrm{P}<0,05)$ ao teste de Tukey.

A umidade dos filés de saramunete (78,23\%) encontra-se próxima do observado para outras espécies de peixes teleósteos de água marinha, como, por exemplo, a biquara 
(Haemulon plumierii) (83,3\%) (Raúl et al., 2018). O objetivo de realizar a lavagem da carne mecanicamente separada é aumentar a vida útil com a lixiviação de alguns componentes como enzimas, compostos ácidos, gorduras, restos de sangue e pigmentos (Durães et al., 2012), além de concentrar as proteínas miofibrilares causando mudanças nos aspectos de textura (Tenuta Filho \& Jesus, 2003). No entanto, a lixiviação desses componentes tende a aumentar a propriedade hidrofílica do músculo e dificultar a remoção da água (Barrero \& Bello, 2000). Esse fenômeno foi observado no presente estudo, em que a porcentagem média de umidade com até duas lavagens aumentou na CMS obtida do espinhaço ( $\mathrm{P}<$ 0,05) (Tabela II). Padrões similares foram observados também em lavagens da CMS de resíduos de filetagem de tilápias do Nilo (Orechromis niloticus), com a umidade aumentando de 81,25\% (sem lavagem) para 87,99\% (duas lavagens) (Oliveira Filho; Viegas; Kamimura \& Trindade, 2012), da CMS de bagre africano (Clarias gariepinus), com a umidade passando de 78,42\% (sem lavagem) para 84,26\% (duas lavagens) (Durães et al., 2012), e em filés moídos de panga (Pangasius sutchi) submetidos a três lavagens, com a umidade passando de 73,97\% para 82,26\% (Majumdar; Debbarma \& Pal, 2016). Além de causar mudanças na textura e cor, o aumento da umidade da CMS pode também propiciar desenvolvimento microbiano (Oliveira Filho; Viegas; Kamimura \& Trindade, 2012). Portanto, o uso de equipamentos como centrífugas ou prensas hidráulicas é recomendado para manter a umidade da CMS submetida a lavagens próxima do valor observado sem lavar (Barrero \& Bello, 2000).

A carne de pescado possui quantidade de nitrogênio total compatível à de animais terrestres, além da presença de todos os aminoácidos essenciais (Oliveira Filho et al., 2010). Os filés de saramunete apresentaram alto teor proteico médio $(19,22 \%)$, superior ao observado na CMS do espinhaço sem lavar, com uma ou duas lavagens (Tabela II). O menor valor de proteínas na CMS pode ser consequência da maior quantidade de gordura na CMS em relação aos filés (Tabela II).

Houve diminuição $(\mathrm{P}<0,05)$ da porcentagem de proteínas na CMS à medida que se aumentou o número de lavagens (Tabela II), o que pode ter ocorrido devido à lixiviação das proteínas sarcoplasmáticas e nitrogênio não proteico, que são solúveis em água (Durães et al., 2012). Com a lixiviação das proteínas sarcoplasmáticas, que são enzimas, pode ocorrer um aumento da vida útil do produto e maior concentração de proteínas miofibrilares, melhorando assim, também, a elasticidade de produtos elaborados com essa carne. Em outros estudos, diminuição na porcentagem de proteínas totais com a lavagem da CMS também foi observada. A CMS de resíduos de filetagem de tilápias do Nilo apresentou diminuição da porcentagem de proteína, passando de 11,02\% para 6,72\% (duas lavagens), perda de 39,1\% de proteínas (Oliveira Filho; Viegas; Kamimura \& Trindade, 2012). A CMS de bagres africanos (Clarias gariepinus) passou de 15,86\% para 11,05\% (duas lavagens), perda de 30,33\% de proteínas (Durães et al., 2012), e a CMS de sardinha (Sardinella aurita) diminuiu de 14,67\% para 12,72\% (três lavagens), perda de 13,29\% (Barrero \& Bello, 2000). Quando se compara com o presente estudo, observa-se que a porcentagem de perda de proteínas com até duas lavagens da CMS obtida dos espinhaços de saramunetes é de 44,47\%. Essa variação na porcentagem de retirada de proteínas com as lavagens da CMS de pescado pode ocorrer devido a diversos fatores, como a composição centesimal da carne, o tempo de lavagem, a relação entre quantidade de água e CMS, o tipo de remoção da umidade final do produto, se é realizado de forma manual ou com equipamentos, e o tipo de equipamento utilizado (centrífugas ou prensas hidráulicas). O processo de lavagem da CMS de saramunetes foi realizado de maneira similar ao utilizado por Oliveira Filho, Viegas, Kamimura e 
Trindade (2012), ou seja, utilizando três partes de água gelada $\left(1^{\circ} \mathrm{C}\right)$ para uma parte de CMS, misturando o material por 2 minutos, deixando em repouso por 3 minutos, posteriormente filtrando o material em saco de nylon e prensando manualmente até a retirada do excesso de água. Essa pode ser a explicação da perda próxima de proteínas entre as CMS de tilápias (Oliveira Filho; Viegas; Kamimura \& Trindade, 2012) e saramunetes, apesar de se tratar de espécies diferentes.

Os filés de saramunete apresentaram baixa porcentagem de lipídeos (0,25\%) (Tabela II). A CMS obtida do espinhaço apresentou porcentagem de lipídeos ligeiramente superior ao observado nos filés, provavelmente em decorrência do espinhaço conter parte da região abdominal do peixe e a gordura da mesma poder ser incorporada na CMS após o processamento na máquina desossadora.

O aumento do número de lavagens da CMS resultou na diminuição de 76,12\% de lipídeos totais (Tabela II). Em outros estudos também foram observadas tendências similares. Por exemplo, em até duas lavagens da CMS obtida de espinhaço de tilápias do Nilo (Orechromis niloticus), houve a diminuição de 36,82\% de lipídeos, passando de 6,22\% para 3,93\% (Oliveira Filho; Viegas; Kamimura \& Trindade, 2012), diminuição de 29,12\% de lipídeos com até duas lavagens da CMS de bagre africano (Clarias gariepinus), passando de 3,88\% para 2,75\% (Durães et al., 2012), diminuição de 54,33\% com até três lavagens da CMS de sardinha (Sardinella aurita), passando de 7,65\% para 3,48\% (Barrero \& Belo, 2000), e diminuição de 50,06\% com a lavagem da CMS de panga (Pangasius sutchi), passando de 7,61\% para 3,80\% (Majumdar; Debbarma \& Pal, 2016). Com a diminuição na porcentagem de lipídeos totais pode haver aumento da vida útil da CMS, pela redução na possibilidade de ocorrer oxidação lipídica.

A porcentagem de cinzas da CMS sem lavar $(1,28 \%)$ foi maior $(\mathrm{P}<0,05)$ que a dos filés $(1,20 \%)$ (Tabela II). Esse valor superior de cinzas na CMS em relação ao encontrado nos filés pode ter ocorrido porque pequenos fragmentos de ossos moídos das espinhas podem ter sido incorporados à CMS. Assim como ocorreu com as proteínas e lipídeos, também houve diminuição na porcentagem de cinzas na CMS de saramunete após a lavagem, indicando que uma parte dos componentes minerais é perdida no decorrer do processo. Esse fenômeno também ocorreu em lavagens da CMS obtida de outras espécies de peixes marinhos e de água doce. Barrero e Bello (2000) observaram diminuição de 65,36\% de cinzas com até três ciclos de lavagens de CMS de sardinha (Sardinella aurita), passando de 1,27\% para 0,44\%. Em outro estudo, Oliveira Filho, Viegas, Kamimura e Trindade (2012) verificaram diminuição de 29,07\% de cinzas com até dois ciclos de lavagens de CMS obtida de espinhaços de tilápias do Nilo (Orechromis niloticus), passando de 0,86\% para 0,61\%. Durães et al. (2012) estudaram o efeito de até dois ciclos de lavagens da CMS de bagre africano (Clarias gariepinus) sobre a porcentagem de cinzas, observando diminuição em $49,01 \%$, passando de $1,51 \%$ para $0,77 \%$. Além da porcentagem total de cinzas, os minerais ferro, magnésio, fósforo, sódio e o potássio também têm uma parte de suas concentrações perdidas, como o observado com até duas lavagens com água de CMS de resíduos de filetagem de tilápias do Nilo (Oreochromis niloticus) (Oliveira Filho; Viegas; Kamimura \& Trindade, 2012).

Apesar de a lavagem da CMS causar aumento da vida útil do produto, utiliza muita água, aumentando os custos de produção. Essa água residual, caso não seja tratada adequadamente, por ser um material rico em compostos orgânicos, possui um alto potencial poluente. Outro fator importante é que com as lavagens o processo também se torna mais 
demorado, o que pode também ser um risco do ponto de vista de contaminação microbiana. Por isso, deve-se avaliar se a CMS de pescado deve ser lavada ou não. Caso seja lavada, deve-se realizar o mínimo possível de lavagem, a fim de que seja mantido um produto com boas características tecnológicas e com o mínimo de interferência possível nas características nutricionais.

\section{CONCLUSÃO}

Os saramunetes (Pseudupeneus maculatus) apresentam rendimento de filés ligeiramente inferior quando comparados com outros peixes de água doce e salgada. Por outro lado, o rendimento da carne mecanicamente separada (CMS) em relação ao espinhaço do saramunete é de aproximadamente $50 \%$, ou seja, próximo ao observado em outros peixes comerciais, mostrando-se, assim, um produto tecnológico que pode ser utilizado na elaboração de salsichas, nuggets e fishburgers. A CMS obtida do espinhaço de saramunete sem lavar com água apresenta boa composição química por ser próxima ao do filé. Portanto, recomenda-se a não lavagem da CMS de saramunetes para evitar perdas de compostos nutricionais (proteína, lipídeos e cinzas) e a formação de resíduos líquidos.

Agradecimentos - Agradecemos à Fundação de Amparo à Ciência e Tecnologia do Estado de Pernambuco (Facepe) pelo Auxílio a Projetos de Pesquisa (APQ), Processo nº. 0023-5.06/15.

\section{REFERÊNCIAS BIBLIOGRÁFICAS}

Alcalde, L.B.; Cavenaghi-Altemio, A.D. \& Fonseca, G.G. Effect of treatments and washing cycles on the quality of Nile tilapia (Oreochromis niloticus) protein concentrate. J. Fish., v. 5, n. 2, p. 483-488, 2017.

Association of Official Analytical Chemistry - AOAC. Official methods of analysis of AOAC, $16^{\text {th }}$ ed. Washington DC: P. Cunniff, 1999.

Arvanitoyannis, I.S. \& Tserkezou, P. Fish waste management, p. 263-309, in Boziaris, I.S. (ed.), Seafood processing: technology, quality and safety. Hoboken: John Wiley \& Sons, 488 p., 2014.

Barrero, M. \& Bello, R.A. Characterization of sardine minced flesh (Sardinella aurita) washed with different solutions. J. Aquat. Food Prod. Technol., v. 9, n. 3, p. 105-114, 2000.

Borgogno, G.; Husein, Y.; Secci, G.; Masi, S. \& Parisi, G. Technological and nutritional advantages of mechanical separation process applied to three European aquacultured species. LWT - Food Sci. Technol., v. 84, p. 298-305, 2017.

Brasil. Boletim estatístico de pesca e aquicultura do Brasil, 2011. Brasília: República Federativa do Brasil. 2012.

Brasil. Regulamento da Inspeção Industrial e Sanitária de Produtos de Origem Animal (RIISPOA). 2017. Disponível em: http://www.agricultura.gov.br/noticias/diariooficial-publica-decreto-do-novo-regulamento-de-inspecao-industrial-e-sanitaria. Acesso em: 5 dez. 2019.

Cardoso, L.; Lacerda, A.C.F.; Gonçalves, E.L.T.; Cadorin, D.I.; Bonfim, C.N.C.; Oliveira, R.L.M. \& Martins, M.L. Gill metazoan parasites of the spotted goatfish Pseudupeneus 
maculatus (Ostheichthyes: Mullidae) from the Coast of Pernambuco, northeastern Brazil. Braz. J. Biol., v. 78, n. 3, p. 414-420, 2018.

Castello, J.P. O futuro da pesca da aquicultura marinha no Brasil: a pesca costeira. Cien. Cult., v. 62, n. 3, p. 32-35, 2010.

Durães, J.P.; Oliveira Filho, P.R.C.; Balieiro, J.C.C.; Del Carratore, C.R. \& Viegas, E.M.M. The stability of frozen minced African catfish. Ital. J. Food Sci., v. 24, p. 61-69, 2012.

Food and Agriculture Organization of the United Nations 2018. The State of world Fisheries and Aquaculture - Meeting the Sustainable Development Goals. Roma: FAO, 2018.

Humann, P. \& Deloach, N. Reef fish identification: Florida, Caribbean, Bahamas. $4^{\text {rd }}$ ed., Jacksonville: New World Publications, 548 p., 2014.

Jatobá, R.F. \& Oliveira Filho, P.R.C. Silagem biológica elaborada com resíduos de filetagem de saramunete (Pseudupeneus maculatus). Rev. Bras. Eng. Pesca, v. 10, n. 1, p. 58-68, 2017.

Lago, A.M.; Vidal, A.C.; Schiassi, M.C.; Reis, T.; Pimenta, C. \& Pimenta, M.E. Influence of the addition of minced fish on the preparation of fish sausage: effects on sensory properties. J. Food Sci., v. 82, n. 2, p. 492-499, 2017.

Lazo, O.; Guerrero, L. \& Alexi, N. Sensory characterization, physico-chemical properties and somatic yields of five emerging fish species. Food Res. Int., v. 100, p. 396406, 2017.

Lopes, I.G.; Oliveira, R.G. \& Ramos, F.M. Perfil do consumo de peixes pela população brasileira. Biota Amazôn., v. 6, n. 2, p. 62-65, 2016.

Majumdar, R.K.; Debbarma, S. \& Pal, P. Influence of previous washing process and storage time on chemical composition and sensory quality of Thai Pangas (Pangasius sutchi) minced muscle during frozen storage. J. Aquat. Food Prod. Technol., v. 25, n. 3, p. 288-298, 2016.

Okasaki, E. \& Kimura, I. Frozen surimi and surimi-based products, p. 209-235, in Boziaris, I.S. (ed.), Seafood processing: technology, quality and safety. Hoboken: John Wiley \& Sons, 488 p., 2014.

Oliveira Filho, P.R.C.; Viegas, E.M.M.; Kamimura, E.S. \& Trindade, M.A. Evaluation of physicochemical and sensory properties of sausages made with washed and unwashed mince from Nile tilapia by-products. J. Aquat. Food Prod. Technol., v. 21, n. 3, p. 222-237, 2012.

Oliveira Filho, P.R.C.; Netto, F.M.; Ramos, K.K.; Trindade, M.A. \& Viegas, E.M.M. Elaboration of sausage using minced fish of Nile tilapia filleting waste. Braz. Arch. Biol. Technol., v. 53, n. 6, p. 1383-1391, 2010.

Olsen, R.L.; Toppe, J. \& Karunasagar, I. Challenges and realistic opportunities in the use of by-products from processing of fish and shellfish. Trends Food Sci. Tech., v. 36, n. 2, p. 144-151, 2014.

Priyadarshinia, B.; Xavier, K.A.M.; Nayak, B.B.; Dhanapal, K. \& Balange, A.K. Instrumental quality attributes of single washed surimi gels of tilapia: Effect of different washing media. LWT - Food Sci. Technol., v. 86, p. 385-392, 2017.

Raúl, L.J.; Araújo, I.B.; Barbosa, R.C.; Maciel, M.I.S.; Shinohara, N.K.S. \& Oliveira Filho, P.R.C. Manufacture of biquara (Haemulon Plumierii - Lacepède, 1801) fishburger with addition of wheat bran. J. Aquat. Food Prod. Technol., v. 27, n. 5, p. 544-556, 2018. 
Santana, F.M.; Morize, R. \& Lessa, R. Age and growth of the spotted goatfish, Pseudupeneus maculatus (Bloch, 1793) in Brazil, validated through marginal increment and oxytetracycline dyes in the sagittae. J. Appl. Ichthyol., v. 22, n. 2, p. 132-137, 2006.

Santos, F.K.; Vasconcelos Filho, M.B.; Vieira, P.H.S.; Malheiros, L.S. \& Oliveira Filho, P.R.C. Rendimento corporal do saramunete, Pseudupeneus maculatos (Bloch, 1793), submetido a diferentes métodos de filetagem. Arq. Ciên. Mar, v. 49, n. 2, p. 15-22, 2016.

Secci, G.; Borgogno, M.; Mancini, S.; Paci, G. \& Parisi, G. Mechanical separation process for the value enhancement of Atlantic horse mackerel (Trachurus trachurus), a discard fish. Innov. Food Sci. Emerg., v. 39, p. 13-18, 2017.

Silva, M.A.P.; Vieira, P.H.S. \& Oliveira Filho, P.R.C. Elaboração de fishburger de saramunete (Pseudupeneus maculatos) utilizando diferentes tipos de farinhas vegetais. Rev. Bras. Eng. Pesca, v. 9, n. 2, p. 36-51, 2016.

Souza, M.L.R.; Macedo-Viegas, E.M.; Zuanon, J.A.S.; Carvalho, M.R.B. \& Goes, E.S.R. Processing yield and chemical composition of rainbow trout (Oncorhynchus mykiss) with regard to body weight. Acta Sci. Anim. Sci., v. 37, n. 2, p. 103-108, 2015.

Tenuta Filho, A. \& Jesus, R.S. Aspectos da utilização de carne mecanicamente separada de pescado como matéria-prima industrial. Bol. SBCTA, v. 37, n. 2, p. 59-64, 2003. 